\title{
Materials to boost companies innovation. Systemic production network and technological crossbreed
}

\author{
Lerma, Beatrice $^{\mathrm{a}}$ \& Dal Palù, Doriana ${ }^{\mathrm{b}}$ \\ ${ }^{a}$ Department of Architecture and Design. Politecnico di Torino, Italy. beatrice.lerma@polito.it \\ a Department of Architecture and Design. Politecnico di Torino, Italy. doriana.dalpalu@polito.it
}

\begin{abstract}
The origin of resources and location of suppliers and manufacturers are key elements in environmental sustainability. Equally important are the potential new areas of application and the development of further production. The aim of this article is to investigate how designers can help manufacturing companies providing sustainable solutions that envisage a future beyond processes, by considering the complexity of a territory and its production system. The creation of "zero-km" contacts network among companies, dealers, producers and suppliers could be useful for Small and Medium Enterprises (SMEs) in order to improve their production in a sustainable way. Moreover, developing new products and investigating on new potentialities of the currently produced series drive manufacturing companies towards (eco) innovation. Doing so through envisioning unconventional interpretations for materials, semi-finished products and components alike, through technological crossbreed.
\end{abstract}

This is the direction through which material libraries should seek to progress: in fact on the one hand today's materials and production/finishing processes are smart and encase performance and functionalities that require complex systems. On the other hand the origin of resources and localization of local suppliers and manufacturers are key elements when it comes to environmental sustainability.

The article presents an analysis of the potentialities of material libraries and the activity of an academic material library, conceived not only as an archive but also as a support to boost companies' innovation management. In this last case, the support offered to firms is characterized by a strong design slant and ensures the methodologies and principles of Eco-Design, Exploring Design and Advanced Design (ADD) paths: following these methodologies, solutions related to firms productive district are defined, taking into consideration materials/semi-finished products that can be renewed by transferring them to different manufacturing cycles.

In material libraries the designer's role is to transform the intangible aspects associated with territorial and technological dimensions into tangible solutions. This article will present case studies of SMEs working in different fields, which started to produce new objects and updated their production using new materials and semi-finished products. 
Keywords: Materials libraries; sustainable strategies; companies' innovation; design research; Advanced Design.

\section{From the materials' hyper-choice to the materials archives: Their role in a local context}

Currently, around the world, there are millions of different materials and new ones are constantly springing up: "the proliferation of new materials and the enormous technical and expressive possibilities offered mean designers must keep continuously updated on their properties and possible applications" (Langella, 2003); in fact the designer and manufacturer are faced with a huge and growing scope of possibilities, in which the choice of materials and the transformation processes can be combined, giving rise to what is known as "hyper-choice" (Manzini, 1986).

In order to search for and classify innovative materials and products for the world of architecture, design and industrial production, "material libraries" have been created; real and virtual archives of indexed material samples that are offered to designers as research tools in an attempt to increase awareness of all the materials available (De Giorgi, 2012). The term "material library" is a neologism, coined to identify physical or virtual places in which technical information is collected and made available in relation to a wide range of materials, particularly in the world of architecture, design, fashion and industrial production in general (Lerma, De Giorgi \& Allione, 2013). "For some designers, material libraries are primarily centres in which to find inspiration for new projects; there are people who consider them as places to visit, like a contemporary sculpture exhibition or a 'documentary' of current affairs, in which 'curious' simple materials with an extra-terrestrial aspect become major protagonists or collector's items [...]. For others, they are considered places in which to work, to conduct in-depth research on a specific component with the possibility of drawing upon the expertise of consultants [...]" (Campogrande, 2009).

As Dehn underlines (Dehn, 2014), materials have become "more sophisticated in appearance and performance and most of them were in production": the possibility to give access to samples and information on a variety of materials and technologies has become fundamental for students, professionals and companies in order to be up-to-date in terms of material and technology innovations. In fact, material libraries are not just born from the need to assist the designer in gathering information on new materials, but also to help companies promote their products on the market, to become part of a community and thereby gain contact more quickly with other organizations, to build solid collateral and publicity and to meet potential new customers or partners: creating a network of contacts in the territory facilitate the manufacturing companies, particularly the Small and Medium Enterprises (SMEs), while selecting their suppliers or researching and evaluating local partners for processing operations. This is the direction in which material libraries should seek to progress in order to support SMEs innovation.

\subsection{Materials for sustainability dimension: Supply chain and production systems}

When it comes to environmental sustainability, opting for the use of materials and semi-finished products sourced from areas comparable to that where the company operates is strongly advisable (Lerma, 2014); in fact, planning and organizing a short production chain is akin to keep down logistic costs, harmful emissions (e.g. $\mathrm{CO}_{2}$ ) to the air, distance to move goods within, thus resulting in an improved quality of the distribution chain (Marino, 2013). On the other hand, the sustainable supply chain requires conscious choices to be made at all industrial stages: from the purchase department, through to product development, Marketing, Transport and Logistics organization" (Colicchia, 2012). According to the 
Cluster Theory, a.k.a. conglomerate theory or cluster (Lanzavecchia, Barbero \& Tamborrini, 2012), the local economy could greatly benefit from companies part of the same cluster that share and interconnect raw materials and suppliers. Conversely, companies have instead a scarce knowledge of who their neighbours are and what their productions are all about, so much so, that they end up liaising with faraway suppliers and transformation partners: the logistics activity, referred both to distribution chain and the actual/organizational product management, gets tangled, hence, it weighs more on environment.

Local SMEs and manufacturing companies will be able to reduce waste and consumption and optimize the use of resources, as well as encouraging the pre and post consumption use and re-use of waste throughout the production process, by adhering to a sustainable logistics, that is more efficient and sensitive to the ecosystem requirements (Aguiari \& Provedel, 2013).

\subsection{MATto materials library of Politecnico di Torino: A consultancy service for SMEs of the Piedmont Region}

MATto materials library of Politecnico di Torino (Design and Visual Communication Degree Course) is a material archive, which includes more than 700 samples of new generation materials, particularly used in the field of design and architecture. MATto has been developed in the Politecnico di Torino Design Course, also with the help of the students, in order to keep designers up to date about the latest materials available for their projects. Up to now, for each MATto material samples, an analysis sheet is arranged, which reports the technical (physical-mechanical) properties of the materials, its applications, the available format and a cost estimation (Ashby \& Johnson, 2002). MATto is aimed at becoming a support tool for the problem setting, by which the designers (and the other figures involved into the product development) are assisted for identifying which material parameters influence the product ecoperformances. Consequently, a multidimensional profile is provided and the several parameters are not averaged in a unique performance indicator (Graedel, 1997). At the same time, another important information provided by MATto material library is the sensory profile, which could be useful for considering the human perception of materials too. 


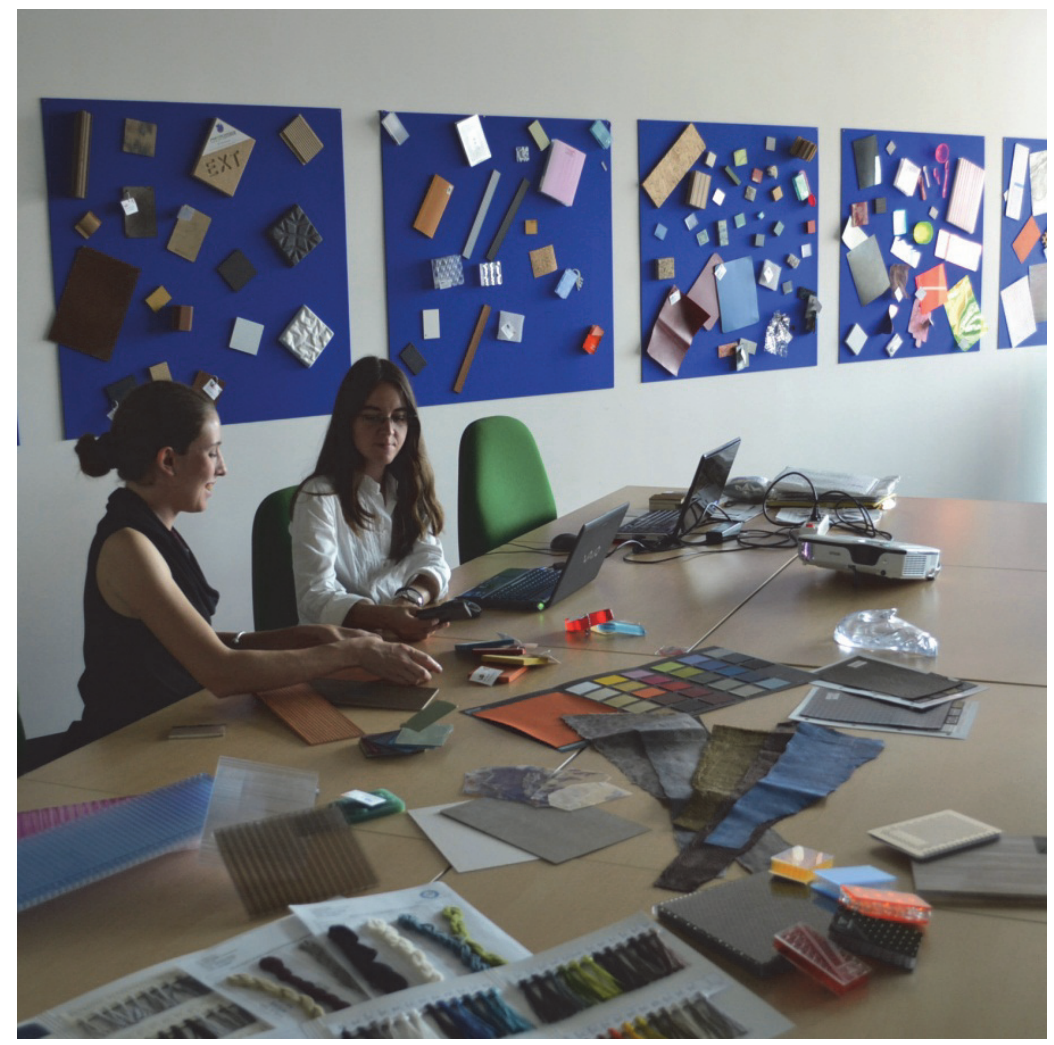

Fig. 1 MATto material library in Politecnico di Torino: the exposition and a phase of the consultancy service

In 2010, it has become a consultancy service (fig. 1) supported by Torino Chamber of Commerce for the SMEs of the Piedmont Region in Italy (De Giorgi, 2012). The innovative aspect of MATto is to provide meta-project solutions, in other words some indications to the design process without the specific solutions that will be subsequently implemented, by identifying new materials or semi-finished products suitable for every specific need or request of each project, based not only on the technical and economical performances: also the sensory and environmental material properties are considered.

The MATto_Materials for Design consultancy service organized by MATto materials library aims to address companies' needs related to critical product, materials, processes, environmental sustainability of materials, semi-finished products, innovation in their field and new markets for businesses. Materials are identified in order to help companies to develop new products and explore new potential products on the basis of their specific requests. Since 2010, more than 150 firms have taken advantage of the consultancy service and their production fields are various: from the automotive field to jewelry, to packaging to lighting, to technical textiles, to personal accessories, etc.

\section{The research question: How to support SMEs towards a progressive innovation?}

The search for innovative materials and, in particular, for innovative production processes, is fundamental and crucial for every enterprise. Innovative enterprises in fact are constantly looking for new ideas, for a new future product, to obtain improved solutions for a product already in the design process or obtain solutions for a product already in production. 
For SMEs, this issue is far more crucial. In fact, they are the most disadvantaged realities specifically concerning environmental innovation, basically because they cannot invest in, and consequently benefit from, a Research and Development unit (De Giorgi, Dal Palù \& Allione, 2015); furthermore, no permanent educational tool has as yet been provided in support both to the managerial level and to the innovators involved in the enterprises (Halila \& Tell, 2013; Le Pochat, Bertoluci \& Froelich, 2007).

Moreover, revolve around innovation issue is not easy: innovation both in terms of materials and production processes and technologies, is defined not only by applying high innovative materials/technologies/semi-finished products, but also through using "traditional" materials in an innovative way or/and in a new context. Developing new products and investigating over new potentials of the currently produced series drive manufacturing companies towards (eco) innovation through envisioning unconventional interpretations for materials, semi-finished products and components alike, through technological crossbreed.

Both the facts that in SMEs very often there is not the culture of innovation research, as well as the time to do research or people trained to do it, lead these companies in a standstill situation. Design, instead, can supply the drivers to define innovation strategies, in order to obtain concrete results starting from researches: in these terms materials research in MATto is a support to boost companies' innovation management. Researches about innovative materials and production processes are, for designers and researchers of MATto materials library, a median to intervene in design and production processes.

\subsection{Overview of the adopted research methods}

In MATto, the consultancy service MATto_Materials for Design is organized for firms, and especially for SMEs, following some specific methodologies adopted in Politecnico di Torino and typical of the design process, such as: the Advanced design, the Exploring design and the Eco Design guidelines.

In the absence of market, for example, the Exploring Design path allows designers to generate systemproduct, process, service design projects that are always original and innovative, capable of leading quite easily to new methods, business ideas and spheres of activity in which customers can become involved later on. More in details, adopting the Exploring Design path (Germak \& De Giorgi, 2008), a background analysis of the product pointed out both the stereotypes and new possible options representing an innovation (Lerma, De Giorgi \& Dal Palù, 2014). This overview which we call it "scenario analysis", focusses mostly on materials, processes, environmental and social sustainability, and relationships with the productive district, in particular on materials used in the current production system. The research team defines a process scenario that takes into account key details such as company history, currently used technologies, flow of materials and adopted strategies in order to assess the company's starting level of innovation and ecological mind-set (De Giorgi, 2014). In particular, the actual production of the company-case study is analysed, as well as the competitors' products, in terms of innovation, materials, sustainability and processes. Moreover, according to the Eco Design guidelines (Vezzoli \& Manzini, 2007; Tamborrini, 2009; Lanzavecchia, Barbero \& Tamborrini, 2012; Lerma, De Giorgi \& Allione, 2013), focus in particular on the resources of the territory (in particular, the Piedmont Region). As defined by Advanced Design (ADD) discovery and new degree of knowledge can turn into continuous innovation, contributing to create new producers, new production processes, new users and new markets to spread innovation (Lerma, De Giorgi \& Dal Palù, 2014).

Moreover, in MATto, the researches are organized ad hoc for each firm, adopting the Design Thinking, a complex problem-solving method based on analytical phases, multidisciplinary research, brainstorming and the creation of ad hoc strategies; in fact, this method is applied more and more often to business in general: as Branzaglia underlines (Branzaglia, 2014) ADD is aimed to translate technological innovation 
into behaviour innovation. Moreover, this method defines two specific working sectors to designers: defining a context for a new product and a new semi-finished product, and redefining the relationship between different production chains.

\subsection{The technological crossbreed key concept}

"An innovation, originally conceived for a specific production process, subsequently enters products and sectors often far from the expectations of economic promoters" (Penati, 2004). The cross-fertilization phenomena may be a stimulus to the introduction adoption of innovations in companie's production (fig. 2).

Innovative materials come from highly specialized, if not niche sectors; such materials, along with semifinished products, components and surface treatments traditionally applied to sophisticated, high-tech content items, are also used for producing everyday, ordinary utility objects. Companies can find then "new raw materials" for their productions by researching materials and semi-finished products that can be renewed by transferring them on to further manufacturing cycles.

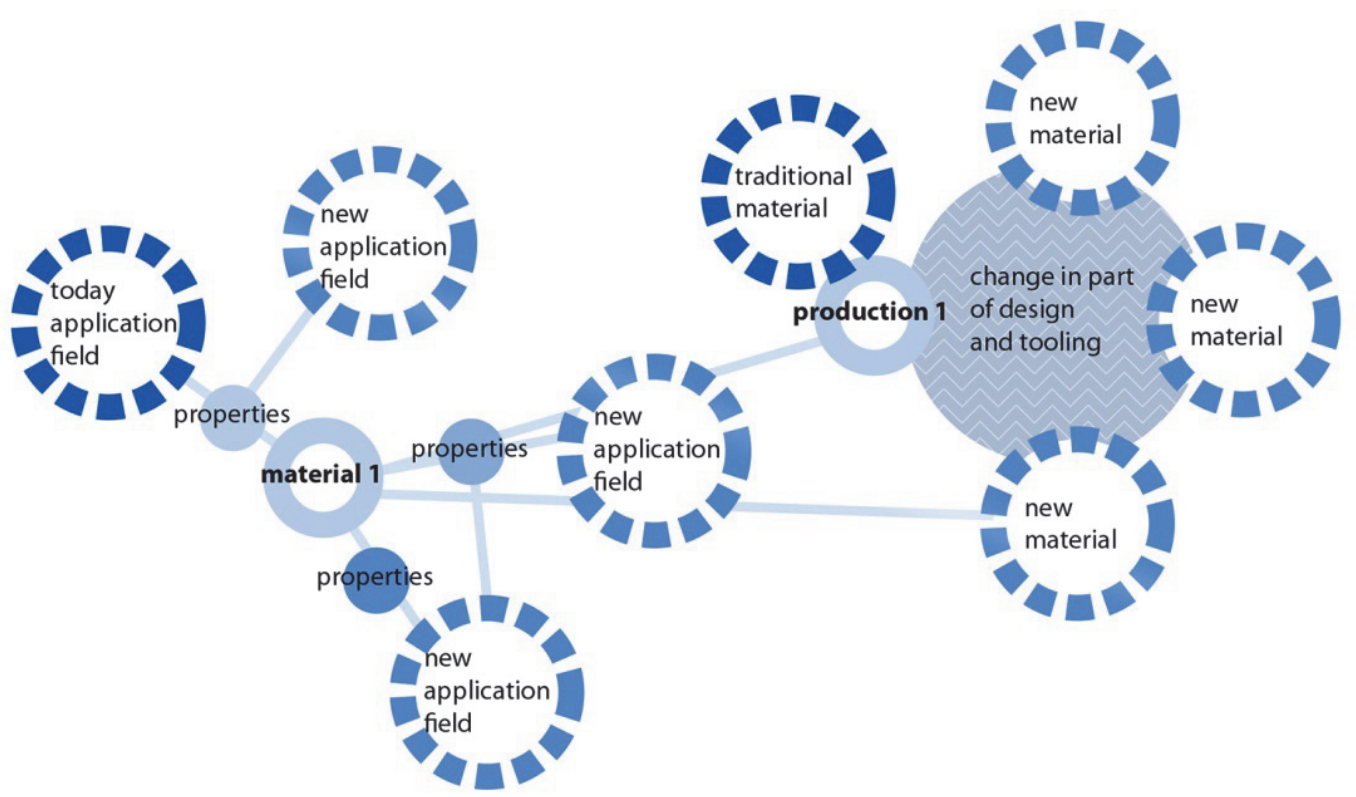

Fig. 2 The technological crossbreed: from a traditional application field to an innovative one

Developing new products and investigating over new potentials of the currently produced series drive manufacturing companies towards innovation through envisioning unconventional interpretations for materials, semi-finished products and components alike.

The technological crossbreed represents then a cross-feritilization approach often adopted by the MATto researchers. Thanks to this approach, the firm can take advantage from the experience already reached in a specific context in which that specific technology or material was traditionally adopted, and move those expertise into its new productive context. In the next paragraphs several results generated by the disclosed research methods applied to the MATto_Materials for Design consultancy service will be presented. 


\section{Results}

Over the past six years, more than 150 firms have taken advantage of the MATto_Materials for Design consultancy service. The production fields of the supported companies varied from time to time: they ranged from the automotive field to jewellery, packaging, lighting, technical textiles, personal accessories, etc. Each researches was organized ad hoc for each firm, following the specific needs and requirements in innovation. Several case studies could be presented in order to show the results reached thanks to the support of the consultancy service. In this contribution, two meaningful examples will be disclosed.

\subsection{Case study \#1: New materials for sustainable luxury}

The role of designers of MATto material library in this case was to investigate how sustainable design can help a prestigious goldsmith company which faced financial difficulties in identifying new strategies in selecting materials for their jewelry creation. Therefore helped the firm to preserve their luxury levels and their market positioning, as well as retaining their target audience, and focusing on new more eloquent and environmentally bearable opportunities (Lerma, De Giorgi \& Dal Palù, 2016, in press) (fig. 3).

The proposals defined by the research team were linked to environmental and material lightness, territory and different productive chains. More in details (De Giorgi, 2014), the choice was about light alloys used in the aeronautics and aerospace fields (aluminium and titanium alloys); in fact, the goldsmith company territorial location also housed an international outpost of aerospace fields.

According to previous background analysis about jewels and company production, the recently soaring price of gold and the considerations following the eye-tracking analysis (on jewels and other products) about the importance of elegance (Buiatti, 2013), the research group defined several ways in which gold can coexist with other metals: the main proposal focused on the surface finishing, which can transform the visual perception of the material, while retaining its intrinsic characteristics. In particular, the defined finishing colour was black: this colour, in fact, is generally linked to semantic areas of elegance and preciousness. This solution was defined in order to maintain the company corporate identity and elegance: the focus was then placed on surface finishing available with a specific advanced finishing technique (DLC), similar to PVD, but more performing, used in healthcare and automotive fields and able to ensure biocompatibility, wear and corrosion resistance and availability to carry both a matt or glossy finishing. 


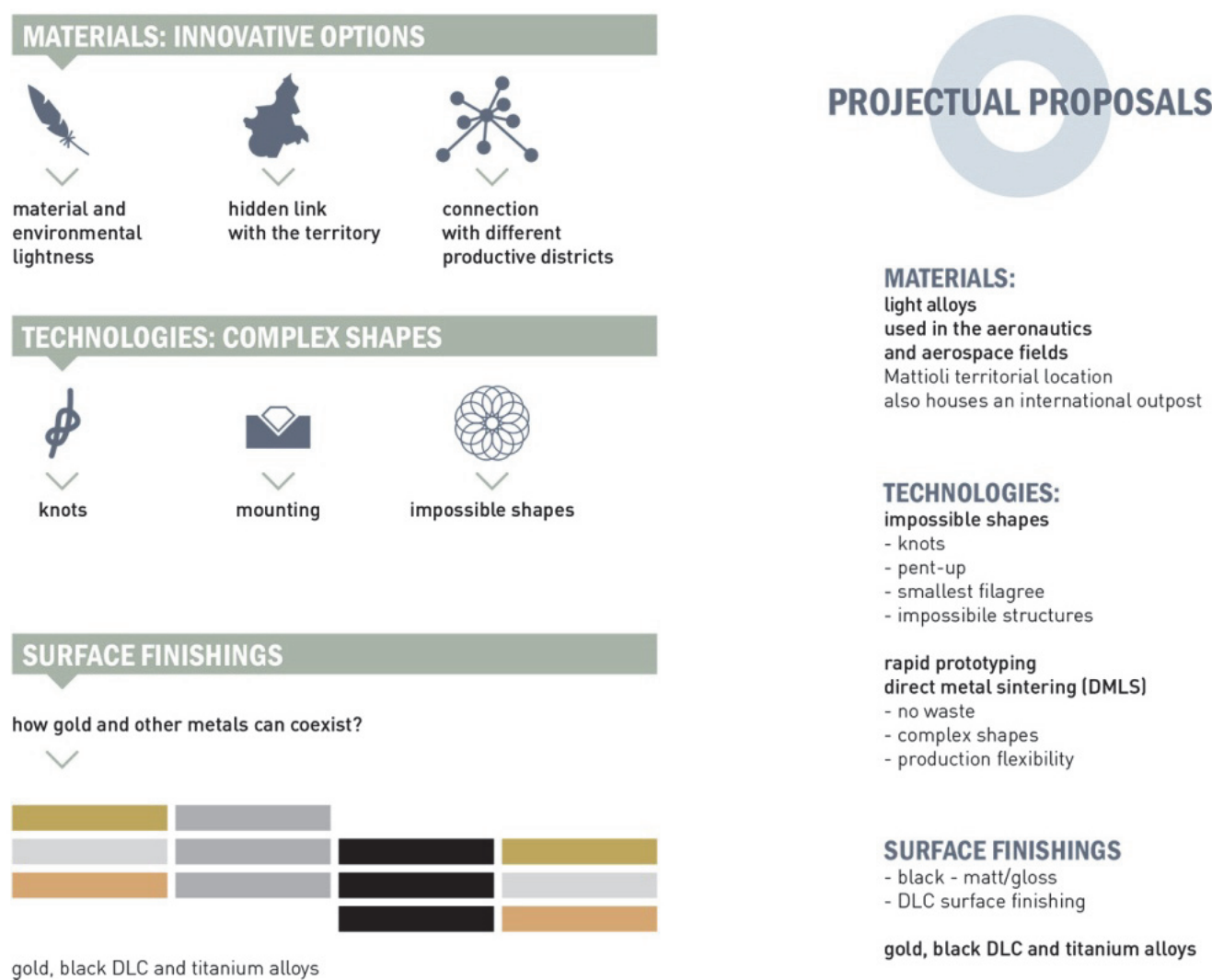

Fig. 3 Innovative materials and projectual proposals for jewellery case study (credits: De Giorgi, 2014)

Specifically, the hypothesis of black finishing was tested by the firm through a prototyping phase and several mechanical tests (Maleck De Oliveira Cabral, 2013). The DLC process is a plasma-assisted chemical vapour deposition (PACVD) technology used to apply the diamond-like carbon to the watches; moreover, Diamond-like carbon, or DLC, is amorphous carbon plasma - a material that exhibits astounding properties whose, for years, have benefitted a variety of industries including aerospace, military, medical and automotive industries that constantly demand new heights of material innovation.

The cross-fertilization operated thanks to a technological crossbreeds from aerospace, military, medical and automotive sectors to the jewelry sector could provide some alternatives to the traditional materials, in order to emphasize the "project value" and the "innovation value", instead of the traditional gold preciousness. The goldsmith company introduced this technological innovation in several of its jewels collections and are currently on the market. Furthermore, they benefited of several advantages: thanks to the "black gold" they strengthened the brand identity, the perceived luxury of the product as well as the market positioning; at the same time, minimizing the gold quantity usage and they also controlled the costs of this new environmentally friendly collection.

\subsection{Case study \#2: The innovative dimension of digital decoration}

In 2015, MATto started a collaboration with a SME, leader in digital decoration located in Piedmont Region, looking for new commercial partners. The collaboration with this company was conceived as a new opportunity offered by MATto to the Italian and international productive firms of materials and semi finished products to experience for free the potential of the digital decoration, directly on their products, adopting a win-win strategy. 
The digital decoration process is proposed for reproducing every graphic idea (pictures, patterns but also flat colours) on a wide rage of materials, going from wood to glass, paper, textiles, aluminum, steel, copper, ceramics, stone, leather, PVC (polyvinyl chloride), PMMA (polymethyl methacrylate, i.e. Plexiglass) and many other materials; with this technique is possible to customize and tailor products and semi finished products, by realizing opaque or transparent decorations, in high definition quality and with a perfect integration colour-material (fig. 4).

Several opportunities are offered to productive firms, and right the innovative potential of this new technique was at the basis of the consultancy service. Some of the opportunities ranged from testing the monochromatic colourings, to realize vectorial patterns, decorate with bitmap images, using four-colour printing with transparent (CMYK) or opaque (CMYK-W) finishing, opaque white (the firm can control also the opaqueness gradient), transparent inks (another opportunity is to test the matte effect, with the ability to control the matte gradient), four-colour opaque (CMYK-W) printing. Moreover, it is possible to print more than 16.000 .000 possible colours, in high resolution (up to $1400 \times 1400 \mathrm{dpi}$ ), with non-toxic water-based organic inks (with an advantage given by a stronger chromatic power, and the possibility to create more details) and in absence of materiality and thickness of decorated parts (this technique generates no "gap-effect").
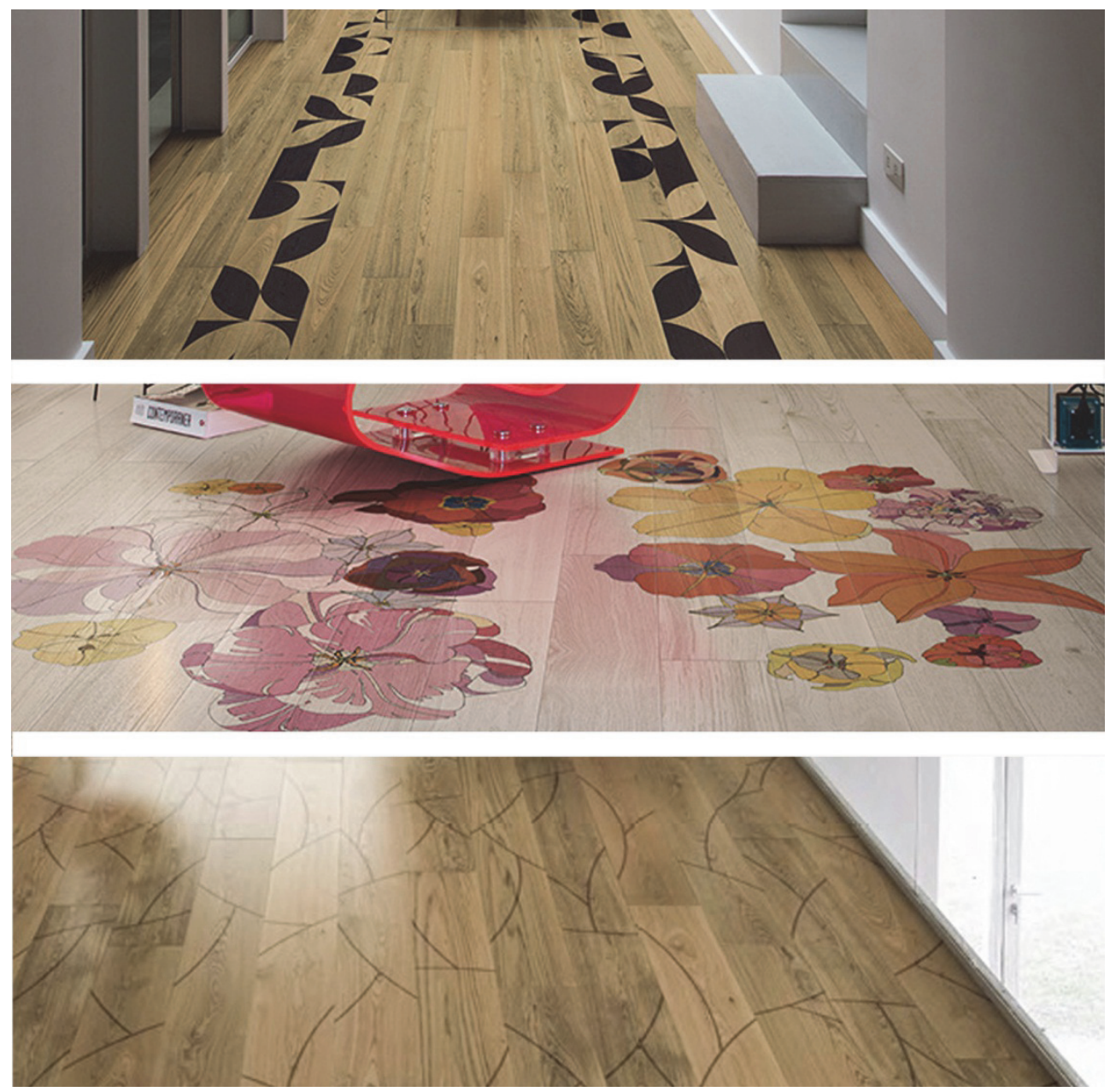

Fig. 4 Digital decoration on wood: Geometrico, Tulipae Gemini and Ramoscelli | DESIGN collection, by Xilo 1934 
Thanks to presence of different suppliers of the digital decorative company in the Centre of Italy and in other Countries in the world (such as in Spain and in Portugal), the digital decoration could be presented not only in a local context, but also internationally.

The opportunity to test the digital decoration on its own material samples was spread through the MATto communicative channels. Companies working in different fields (from floating flooring systems, to furniture and interiors fittings, to acoustic panelling for theaters and opera house producers) and producing various typologies of materials are now testing the digital decoration with positive feedback. Paper with particular coatings that are used in furniture field, leather-no-leather, semi finished products made in wood (innovative in materials composition), wood veneers for interior applications: these are just some of the materials on which the digital decoration was tested in these months, and on which other tests, such as wear resistance and colour brilliance, are currently underway, in order to investigate and improve the technical aspects and feasibility of the adoption of this innovative process in the current production (fig. 5).
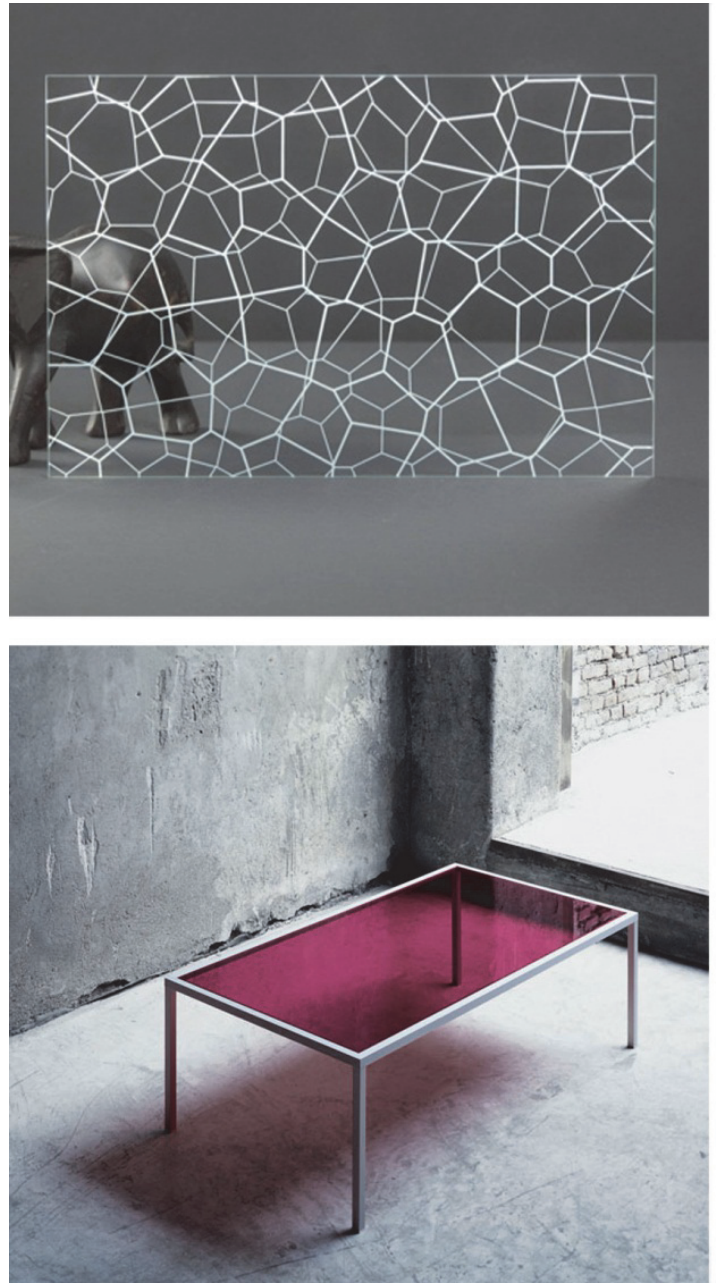
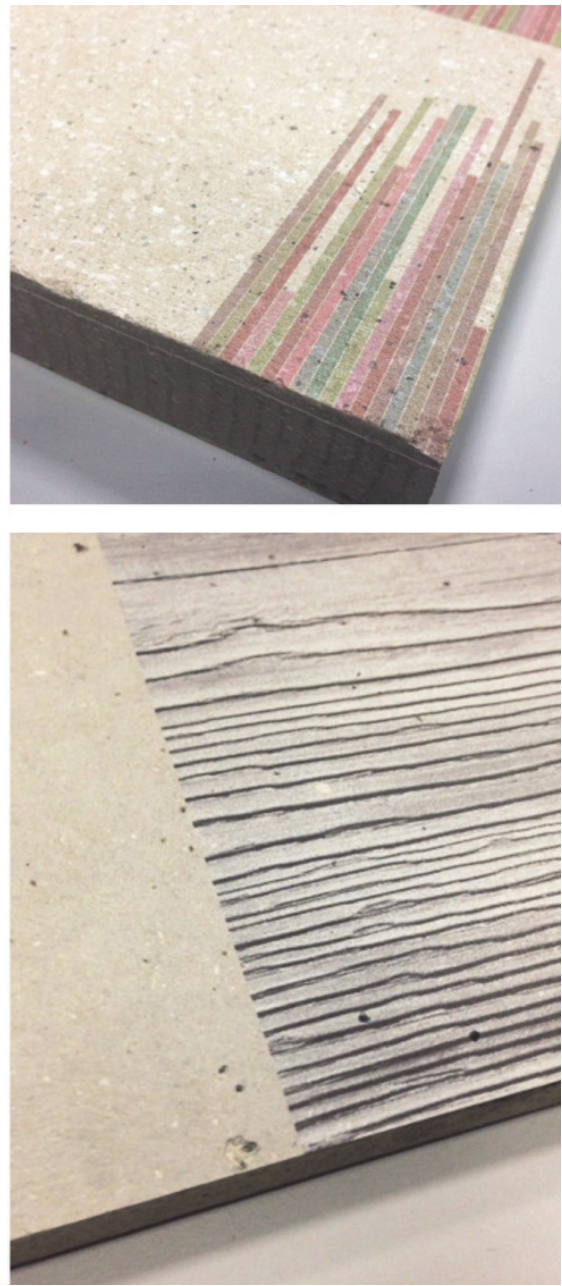

Fig. 5 Digital decoration on other materials: some examples of effects on glass (table Go on Evolution 20, by Glas Italia) and on composites 
In this case, MATto played the role of a connection between a company that offers a specific technology and its new possible clients: MATto identified new possible fields of interest for the current technology object of the research, and focused the firms interested in innovate their production by using a specific innovative coating system. With this aim, thanks to the collaboration with MATto, new high technological level productive synergies were created. National and international productive firms had the opportunity to test the technology for free, and the digital decoration firms obtained new commercial contacts, possibly interested in exploiting its technology.

\section{Conclusion}

The results of the experiences disclosed in the article are useful to provide insights for further applications to small and medium enterprises, researchers, designers and other innovation practitioners. Moreover the researches and consultancy activities in MATto are characterized by a very good satisfactory level. In fact, results presented to SMEs are easy-to-use: MATto materials library is focused on applied research (on-demand researches for each company) to obtain expandable results, such as specific contacts of productive companies in order to apply innovative materials and technologies in productive process.

MATto consultancy service aims to define new possible fields of interest for firms, in particular SMEs, and to create new high technological level productive synergies: reaserches in MATto seek to organized an activity that can't be performed within SMEs.

The case studies previously presented provide examples of firms working in different fields, which started to produce new objects and updated their production using new materials and semi-finished products, thanks to the consultancy service provided by MATto materials library. Moreover, the adopted methodologies could be applied in different productive fields: developing new products and investigating the new potential of the current ranges drives manufacturing companies towards eco-innovation by envisioning unconventional interpretations for materials, semi-finished products and components (Lerma, 2014). Thanks to this approach, the solutions presented to firms are not far from to be applied, because in many cases these are already adopted, as traditional materials or technologies, in other specific context.

MATto researchers and designers are able to design the tangible and transform intangible objective into products: the territorial and technological dimensions of researches developed are transformed into tangible solutions thanks to the ADD and Exploring design approaches and the problem solvers designers' ability to identify innovative solutions and strategies useful for companies' production.

\section{References}

AGUIARI, G. y PROVEDEL, R. (2013). Logistica sostenibile: un'occasione di sviluppo \& innovazione. Milano: Franco Angeli, Milano.

ASHBY, M., F. y JOHNSON, K. (2002). Materials and design: The art and science of materials selection in product design. Boston, MA: Butterworth-Heinemann.

BRANZAGLIA, C. (2014). Design di filiera. Il ruolo del design nelle filiere produttive. ADI design codex delegazione Emilia-Romagna. Bologna: Fausto Lupetti Editore.

BUIATTI, E. (2013). "Perception of the sustainability and quality of food packaging - Percepire la sostenibilità e la qualità del packaging alimentare" in De Giorgi, C. Sustainable Packaging? - Packaging Sostenibile?. Torino: Umberto Allemandi \& C.

CAMPOGRANDE, S. (2009). "Diffondere i materiali” in Design follows Materials. Firenze: Alinea Editrice s.r.l.

COLICCHIA, C. (2012). "Casi di successo per una logistica sostenibile”, in Logistica, n. gennaio. 
DE GIORGI, C, DAL PALÙ, D. \& ALLIONE, C. (2015). "Development and results of a cross border network project, aimed at the engineering of eco-compatible products" in Journal of Cleaner Production, vol. 106, p. 619631.

DE GIORGI, C. (2012). "MATto - A New Material Libraryat Politecnico Di Torino, Design Course" in Innovation in Design Education. Theory, research and processes to and from a latin perspective. Proceedings of the Third International Forum of Design as a Process. Torino: Umberto Allemandi \& C, p. 75-88.

DE GIORGI, C. (2014). "Mattioli. Not-only-gold: sustainable innovation in jewellery - Mattioli. Non solo oro: l'innovazione sostenibile nella gioielleria" in in Towards conscious design. Research, environmental sustainability, local development / Verso una progettazione consapevole. Ricerca, sostenibilità ambientale, sviluppo locale. Torino: Umberto Allemandi \& C.

DEHN, J. (2014). "Conception and Realization of a Sustainable Materials library" in Karana, E., Pedgley, O. y Rognoli, V. Materials Experience: fundamentals of materials and design. Waltham, MA: Butterworth-Heinemann.

GERMAK, C. y DE GIORGI, C. (2008). "Exploring Design", in Germak C., Uomo al centro del Progetto - Man at the Centre of the Project. Torino: Umberto Allemandi \& C.

GRAEDEL, T. E. (1997). "Designing the ideal green product: LCA/SCLA in reverse" in International Journal of Life Cycle Assessment, vol.2, issue 1, p. 25-31.

HALILA, F. y TELL, J. (2013). "Creating synergies between SMEs and universities for ISO 14001 certification" in Journal of Cleaner Production, vol. 48, June 2013, p. 85-92.

LE POCHAT, S., BERTOLUCI, G. y FROELICH, D. (2007). "Integrating ecodesign by conducting changes in SMEs" in Journal of Cleaner Production, vol. 15, issue 7, p. 671-680.

LANGELLA, C. (2003). Nuovi paesaggi materici. Design e tecnologia dei materiali. Firenze: Alinea Editrice s.r.1.

LANZAVECCHIA, C., BARBERO, S. y TAMBORRINI, P. (2012). Il fare ecologico: il prodotto industriale e $i$ suoi requisiti ambientali. Milano: Edizioni Ambiente.

LERMA, B. (2014). "Eco-sustainable production networks. From the choice of zero-mile resources to new uses of output. Materials, source and production / Network produttivi ecosostenibili. Dalla scelta di risorse km zero a nuovi impieghi degli output di processo. Materiali, provenienza e produzione» in Towards conscious design. Research, environmental sustainability, local development / Verso una progettazione consapevole. Ricerca, sostenibilità ambientale, sviluppo locale. Torino: Umberto Allemandi \& C.

LERMA, B., DE GIORGI, C. y ALliONE, C. (2013). Design and materials. Sensory perception_sustainability project. Milan: Franco Angeli.

LERMA, B., DE GIORGI, C. y DAL PALÙ, D. (2016). "Sustainable luxury: the new black gold. Materials, coatings and processes for sustainable jewels". In: The Value of Design Research - 11th European Academy of Design Conference Proceedings. In press.

LERMA, B., DE GIORGI, C. y DAL PALÙ, D. (2014). "Design without a customer: the Exploring Design path" in AdvanceDesign Cultures: The Shapes of the Future as the Front End of Design Driven innovation: proceedings of the 5th International Forum of Design as a Process - AdvanceDesign Cultures: The Shapes of the Future as the Front End of Design Driven innovation, Guadalajara: Ed. Tecnologico de Monterrey.

MALECK DE OLIVEIRA CABRAL, T. (2013). Studio e valutazione dell'applicabilità del rivestimento DLC in azienda del settore orafo, Trabajo Final de Máster in Jewellery Engineering. Politecnico di Torino, Alessandria [Consulta: 15 de abril 2014].

MANZINI, E. (1986). La materia dell'invenzione. Materiale e progetto.Milano: Arcadia Edizioni.

MARINO, G. P. (2013). "CO Emission Reduction Through a Sustainable Local Suppliers Network of Raw Materials. Focus on a Delicatessen Shop" in Applied Mechanics and Materials, vol. 378, p. 649-654.

PENATI, A. (2004). "Design come motore di innovazione di sistema" in Bertola, P. y Manzini, E., Design multiverso. Appunti di fenomenologia del design. Milan: edizioni polidesign.

TAMBORRINI, P. (2009). Design sostenibile. Oggetti, sistemi e comportamenti. Milan: Electa Editore.

VEZZOLI, C. y MANZINI, E. (2007). Design per la sostenibilità ambientale. Bologna: Zanichelli. 